\title{
Educação Permanente em Saúde uma ferramenta na Estratégia Saúde da Família: Encontro guiado pela Socioclínica Institucional
}

\author{
Permanent Health Education a tool in the Family Health Strategy: Guided meeting by the Institutio- \\ nal Socioclinic
}

\author{
Educación en Salud Permanente una herramienta en la Estrategia de Salud Familiar: Reunión guia- \\ da por la Socioclínica Institucional
}

\section{Adicéa de Souza Ferreira ${ }^{*}$, Ana Lúcia Abrahão da Silva ${ }^{2}$}

Como citar esse artigo. Ferreira, AS; da Silva, ALA. Educação Permanente em Saúde uma ferramenta na Estratégia Saúde da Família: Encontro guiado pela Socioclínica Institucional. Revista Pró-UniverSUS. 2020 Jul./Dez.; 11 (2): 174-179.

\begin{abstract}
Resumo
Objetivo: analisar e discutir a Educação Permanente em Saúde como ferramenta do processo de trabalho da gerência de cuidados dos enfermeiros atuantes na Estratégia Saúde da Família nos encontros guiados pela Socioclínica Institucional. Método: Estudo de abordagem qualitativa com emprego do desenho Socioclínica Institucional, que opera na lógica de transformar a realidade investigada para compreender a pesquisa. Utiliza-se da produção coletiva do conhecimento e troca de saberes e aprenderes entre participantes e pesquisadores. Os encontros ocorreram no segundo semestre do ano de 2019 o universo do estudo foi composto por 13 enfermeiros, sendo 11 atuantes na ESF e 02 enfermeiros pesquisadores. Resultados: Com os encontros construímos três polos de conhecimento sobre a Educação Permanente como ferramenta do processo de trabalho da gerência de cuidados de enfermeiros atuantes na Estratégia Saúde da Família: 1) A importância da Educação Permanente em Saúde como ferramenta no processo de trabalho; 2) A Educação Permanente em Saúde como ferramenta de comunicação; 3) A Educação Permanente em Saúde como indicador do processo de trabalho. Considerações finais: A Educação Permanente em Saúde configura-se como uma ferramenta de mobilização para o processo de trabalho da gerência de cuidados ao se discutir as ações de saúde no âmbito da Estratégia Saúde da Família.
\end{abstract}

Palavras-chave: Análise Institucional, Enfermagem, Educação Permanente, Estratégia Saúde da Família.

\begin{abstract}
Objective: to analyze and discuss Permanent Health Education as a tool in the work management process of nurses working in the Family Health Strategy in meetings guided by Institutional Socioclinics. Method: Study of a qualitative approach using the Institutional Socioclinical design, which operates in the logic of transforming the investigated reality to understand the research. It uses the collective production of knowledge and the exchange of knowledge and learning between participants and researchers. The meetings took place in the second half of 2019. The study universe consisted of 13 nurses, 11 of whom worked in the FHS and 02 research nurses. Results: With the meetings, we built three poles of knowledge about Permanent Education as a tool in the work process of the care management of nurses working in the Family Health Strategy: 1) The importance of Permanent Education in Health as a tool in the work process; 2) Permanent Health Education as a communication tool; 3) Permanent Health Education as an indicator of the work process. Final Considerations: Permanent Health Education is configured as a mobilization tool for the care management work process when discussing health actions within the scope of the Family Health Strategy.
\end{abstract}

Keywords: Institutional Analysis, Nursing, Permanent Education, Family Health Strategy.

\section{Resumen}

Objetivo: analizar y discutir la Educación Permanente en Salud como herramienta en el proceso de gestión del trabajo de los enfermeros que trabajan en la Estrategia Salud de la Familia en reuniones guiadas por Socioclínicas Institucionales. Método: Estudio de un enfoque cualitativo utilizando el diseño Socioclínico Institucional, que opera en la lógica de transformar la realidad investigada para comprender la investigación. Utiliza la producción colectiva de conocimiento y el intercambio de conocimiento y aprendizaje entre participantes e investigadores. Las reuniones tuvieron lugar en el segundo semestre de 2019 . El universo de estudio estuvo conformado por 13 enfermeras, 11 de las cuales laboraron en la ESF y 02 enfermeras investigadoras. Resultados: Con los encuentros construimos tres polos de conocimiento sobre la Educación Permanente como herramienta en el proceso de trabajo de la gestión asistencial de enfermeras que laboran en la Estrategia Salud de la Familia: 1) La importancia de la Educación Permanente en Salud como herramienta en el proceso de trabajo; 2) Educación en Salud Permanente como herramienta de comunicación; 3) La Educación Permanente en Salud como indicador del proceso de trabajo. Consideraciones finales: La Educación Permanente en Salud se configura como una herramienta de movilización del proceso de trabajo de la gestión del cuidado al momento de discutir acciones de salud en el ámbito de la Estrategia Salud de la Familia.

Palabras clave: Análisis institucional, Enfermería, Educación Permanente, Estrategia de Salud Familiar.

Afiliação dos autores:

${ }^{1}$ Enfermeira. Especialista em Saúde da Família; Especialista em Micropolítica da Gestão e do Trabalho em Saúde do Sistema Único de Saúde; Mestranda do Mestrado Profissional em Ensino da Saúde da Universidade Federal Fluminense-UFF/Niterói. Brasil. E-mail: adiceafer@gmail.com ORCID: http://orcid.org/0000-0002-4977-3835

${ }^{2}$ Enfermeira. Pós Doutora vinculada ao quadro Permanente do Programa de Ciências do Cuidado em Saúde e do Mestrado Profissional de Ensino em Saúde/MPES, UFF, Professora

Titular da Universidade Federal Fluminense, Escola de Enfermagem, RJ, Brasil. Email: abrahaoana@gmail.com ORCID: https://orcid.org/0000-0002-0820-4329 


\section{Introdução}

A Educação Permanente em Saúde (EPS), como uma Política Pública, tem como objetivo nortear a formação e a qualificação dos profissionais inseridos nos serviços públicos de saúde, com a finalidade de transformar as práticas profissionais e a própria organização do trabalho com base nas necessidades de saúde ${ }^{1}$. Ao mesmo tempo, constitui-se como um conceito, visando a um atendimento de maior qualidade aos usuários ${ }^{2}$.

A aprendizagem no trabalho e para o trabalho, parte do pressuposto de que aprender e ensinar, são fatores indissociáveis e se incorporam no cotidiano dos serviços e na interação entre os profissionais. Constituindo uma concepção que norteia ações voltadas para o saber prático e transformador no cotidiano dos serviços ${ }^{3}$.

Analisar, discutir, debater sobre o cotidiano de trabalho em Saúde possibilita pactos e acordos coletivos de trabalho no Sistema Único de Saúde (SUS). Essa aprendizagem dos profissionais de saúde passa a ter sentido quando ela é significativa, ou seja, quando o material a ser aprendido tem algum sentido para o trabalhador ${ }^{4}$.

A bom emprego da EPS, passa a ser presente no cotidiano de várias equipes de saúde, após a publicação da política, principalmente na Estratégia Saúde da Família (ESF) por ser uma proposta de mudança do modelo de atenção vigente. A reorientação do modelo assistencial centra-se na promoção da saúde e prevenção de doenças, com vistas ao desenvolvimento do autocuidado e à melhoria das condições de acesso aos serviços e ações de cuidados à saúde. Neste sentido, a EPS impacta positivamente na construção de novos arranjos no trabalho das equipes de $\mathrm{ESF}^{5}$.

A reorganização da prática e dos processos de trabalho, das equipes de Saúde da Família, tem na EPS uma ferramenta de atualização, capacitação e qualificação dos profissionais. A discussão, coletiva, tem a possibilidade de fortalecer o espaço das ações de saúde nos territórios pelos enfermeiros das equipes da ESF, agindo como um instrumento de aprendizagem no trabalho e pelo trabalho.

$O$ enfermeiro em atuação na ESF contribui para mudanças da EPS uma vez que, as atividades desenvolvidas, por este profissional como elo disparador para a construção de modelagens promissoras do espaço de trabalho ampliando sua inserção, assumindo o ponto de partida inicial em relação aos demais profissionais de saúde por desenvolver gestão, controle social, ensino e assistência consolidado e fortalecendo a Estratégia Saúde da Família.

Este profissional, em suas atividades cotidianas, se envolve com diferentes elementos que fazem parte do trabalho da ESF, indo desde o acompanhamento da prática dos Agentes Comunitários de Saúde, atendimento aos usuários, a articulação com a comunidade para a construção de ações intersetoriais a pactos e compromissos com a gestão local. O trânsito da (o) enfermeira (o), permite um olhar qualificado para os problemas que emergem do cotidiano dos serviços, constituindo, desta forma este profissional, como um dos atores privilegiados na prática da EPS.

Assim evidencia o papel do enfermeiro no âmbito da Estratégia Saúde da Família como um articulador e favorecedor do diálogo e discussão no qual se constrói a produção coletiva de conhecimento. Uma prática que se desenvolve a partir da transformação, de partilhamento de ideias e de reflexões críticas sobre a prática do trabalho das equipes.

A transformação e a produção de conhecimentos em saúde tende de ser participativo. E neste sentido, é importante a construção de modelagens, que tenham como foco a análise das práticas e favoreçam a reflexão sobre os problemas do cotidiano do trabalho em saúde.

A proposta da Socioclínica Institucional, apresenta ferramentas interessantes que possui potencial para provocar a equipe na direção de um processo coletivo de análise de suas práticas, com o compromisso em refletir sobre a realidade do cotidiano do trabalho, em uma produção coletiva de conhecimentos. Uma troca de saberes e aprenderes a qual implica no movimento da EPS.

O presente estudo tem como objetivo analisar e discutir a Educação Permanente em Saúde como ferramenta do processo de trabalho da gerência de cuidados dos enfermeiros atuantes na Estratégia Saúde da Família nos encontros guiados pela Socioclínica Institucional.

\section{Metodologia}

Trata-se de uma pesquisa de abordagem Socioclínica Institucional modalidade desenvolvida por Gilles Monceau nos anos 2000, que se apoia na Análise Institucional, que consiste em uma construção teórico metodológica composta por diversos saberes e práticas, que teve sua origem em torno dos anos de 1960, na França. No Brasil, o institucionalismo foi introduzido a partir de 1970.

O emprego da Socioclínica Institucional, exige um dispositivo, inicial que são elementos como a escrita, o discurso, vídeos, dentre outros, criados para em situações de intervenção, que podem desestabilizar os modos instituídos de funcionamento das instituições, podendo também se tornar um analisador caso consigam colocar alguma situação em análise, revelando a estrutura da instituição, provocando-a e forçando-a à fala ${ }^{6}$.

A Socioclínica Institucional é uma das 
modalidades de pesquisa da Análise Institucional e se desenvolve por meio das oito características que não se constituem em passos de ordenamento obrigatório e pré-estabelecido. São elas:

- A análise da encomenda e das demandas;

- A participação dos sujeitos no dispositivo;

- O trabalho dos analisadores;

- A análise das transformações que ocorrem na medida em que o trabalho avança;

- A aplicação de modalidades de restituição;

- O trabalho das implicações primárias e secundárias;

- A intenção da produção de conhecimentos; a atenção aos contextos e nas interferências institucionais.

Para que essas características sejam evidenciadas, propõe-se a realização de intervenção sobre um determinado problema da realidade, através de encontros Socioclínica, com a finalidade de analisar coletivamente uma situação coletiva ${ }^{7,8}$.

Nessa pesquisa, usamos os encontros de Educação Permanente em Saúde, o qual teve como referencial teórico a Socioclínica Institucional, a Educação Permanente em Saúde já é umas práxis do município onde ocorreu a pesquisa, acontece uma vez na semana de 13:30 hs ás 16:30 hs.

$\mathrm{O}$ que facilitou a realização dos encontros uma vez que, os profissionais participantes não precisaram deixar de realizarem suas atividades nas unidades para participarem da pesquisa.

A pesquisa foi realizada com 11 enfermeiros atuantes na Estratégia da Família de um município da região Serrana do Estado do Rio de Janeiro e 02 enfermeiros pesquisadores sendo 01 deste atuante na atenção básica do município, os critérios de inclusão dos participantes na pesquisa foi ter mais de um ano de atuação como enfermeiro da Estratégia Saúde da Família, os participantes desta pesquisa foram identificados por pseudônimo substituindo seu nome na entrevista, garantindo o anonimato, os convites aos participantes se deu por telefone, pessoalmente e por e-mail pela pesquisadora.

O primeiro encontro ocorreu em uma unidade da Estratégia Saúde da Família em uma sala de reunião reservada com duração de $01 \mathrm{~h}$ e $51 \mathrm{~min}$ com a participação de 09 enfermeiros atuantes na Estratégia Saúde da Família, 01 enfermeiras pesquisadora e 01 enfermeiras analista externo.

Foi apresentada a pesquisa pela pesquisadora e orientadora. Logo em seguida, os enfermeiros apresentaram suas equipes com discussão livre e práticas de ações de saúde no cotidiano da Educação Permanente em Saúde como ferramenta do processo de trabalho da gerência dos cuidados.

Preenchimento do TCLE (Termo de Consentimento Livre e Esclarecido) em duas vias o qual uma via do pesquisador e outra dos participantes, pontou-se também quanto ao ano de formação, tempo de atuação na ESF e titulação acadêmica dos profissionais participantes.

No segundo encontro com duração de $56 \mathrm{mim}$, aconteceu em um espaço reservado e participaram 07 enfermeiros atuantes na ESF, 01 enfermeira pesquisadora e 01enfermeiro analista externo, abordamos algumas questões do cotidiano dos enfermeiros no processo da Educação Permanente em Saúde quanto a gerência de cuidados e a restituição, consiste na devolução da discussão realizada no encontro anterior. Utilizamos equipamentos multimídia, como datashow, o que possibilitou a integração do grupo e facilidade nas discussões.

\section{Resultados e Discussão}

O material produzido nos encontros Socioclínica Institucional, nos permitiu a interação e discussão acerca da Educação Permanente em Saúde como ferramenta do processo de trabalho da gerência de cuidados dos enfermeiros atuantes na Estratégia Saúde da Família.

Dentre os 13 enfermeiros participantes da pesquisa, 02 eram do gênero masculino $(8,4 \%)$ e 11 eram do gênero feminino $(91,6 \%)$, com variações de idades entre 27 e 57 anos e tempo de formação entre 02 anos e 37 anos.

Os dados coletados foram gravados, transcritos e organizados, a partir da leitura do material coletado. A análise se produziram através das características da Socioclínica Institucional, onde procedemos a restituição que consiste em devolver a síntese dos encontros aos participantes.

Com os encontros construímos três polos de conhecimento sobre a Educação Permanente como ferramenta do processo de trabalho da gerência de cuidados de enfermeiros atuantes na Estratégia Saúde da Família: 1) A importância da Educação Permanente em Saúde como ferramenta do processo de trabalho; 2) A Educação Permanente em Saúde como ferramenta de comunicação; 3) A Educação Permanente em Saúde como indicador do processo de trabalho.

\section{A importância da Educação Permanente em Saúde como ferramenta no processo de trabalho}

Trazemos nesse polo a discussão dos participantes da pesquisa dentro da característica da Socioclínica Institucional descrita na metodologia, a qual destacamos a encomenda e a participação dos sujeitos no dispositivo por não se constituir etapas de obrigatoriedade estabelecidas. 
A importância da Educação Permanente em Saúde como ferramenta do processo de trabalho quanto à gerência de cuidados dos enfermeiros em atuação na ESF. A Socioclínica Institucional tem o compromisso em refletir sobre a realidade das práticas produzindo conhecimentos, uma troca de saberes e aprenderes implicando no movimento da EPS.

\begin{abstract}
"E aí, quando você falou a primeira vez, que eu fiquei pensando nesses $60 \%$, eu fiquei pensando nas coisas que a gente precisa de né do trabalho multiprofissional... para a gente poder também resolver, e ai talvez esteja naqueles 40 que você falou que aí a gente vai precisar e para isso precisar ter gerenciamento... que é a reunião de equipe né, ter a Educação Permanente para a gente poder conversar com os Agentes de Saúde, alguma coisa que esteja acontecendo, que seja diferente, alguma novidade, ali, ou como que a gente vai abordar" (Copo-de-Leite)
\end{abstract}

A encomenda "ter a Educação Permanente para a gente poder conversar" é uma solicitação advinda de alguém e seu enunciado, mesmo quando formalizado por escrito, não reflete diretamente a situação em questão, necessitando ser analisado no grupo como um todo ${ }^{7}$.

A participante da pesquisa relata o trabalho multiprofissional e a reunião de equipe atrelados a Educação Permanente em Saúde para a discussão da abordagem processo de trabalho em conjunto com os Agentes Comunitários de Saúde uma vez, que eles são o elo entre a equipe de saúde do território e a comunidade.

A reunião de equipe possui um livro ATA que é um documento da unidade onde são descritas as abordagens, discussões dos casos adstritos dos territórios da Estratégia Saúde da Família, assim como as implementações das ações de saúde a serem realizadas configura-se como uma encomenda já que, é relatada o diagnóstico da intervenção.

Ao trabalhar a partir das solicitações e das encomendas que as acompanham, é preciso reconhecer sua complexidade e os processos institucionais que as induzem. Cada um desses processos segue uma lógica de institucionalização que comporta tensões internas. A negatividade dos processos informa ao pesquisador a sua positividade. A distinção entre esses dois polos não é imediatamente perceptível, ela é produzida pelo trabalho analítico no qual os sujeitos envolvidos estão necessariamente associados ${ }^{8}$.

Todo trabalho Socioclínica situa-se em uma interferência institucional. Essa interferência produz efeitos de transformação e efeitos de conhecimento. Os efeitos de conhecimento são usualmente chamados de resultados da pesquisa, porém esses resultados também podem ser observados nas transformações produzidas na própria situação9.

"Boas ideias têm que ser divulgadas, as coisas legais que estão sendo feitas. Têm que ser mostrado, vai trazer para a (EP) Educação Permanente" (Girassol)
"Estão tentando diminuir a Educação Permanente" (Orquídea)

Salientamos o momento da discussão entre os integrantes das equipes em relação a continuidade da Educação Permanente em Saúde uma vez que, ela acontece uma vez na semana é um espaço de troca de conhecimento e reflexões entre os profissionais enfermeiros da Estratégia Saúde da Família em que são disparadas práticas de ensino-aprendizagem no processo de trabalho.

\section{A Educação Permanente em Saúde uma ferramenta de comunicação}

A discussão da conduta e interação entre os integrantes da equipe ao envolver a Educação Permanente em Saúde como ferramenta de comunicação para melhoria dos processos de trabalho.

\begin{abstract}
"Para promover as nossas ações, futuramente se eu quiser revisitar o que aquele paciente fez se eu quiser saber a conduta dela se ela quiser saber a minha. Então, tem facilitado a nossa comunicação então, eu trouxe alguns instrumentos que estão implantados a gente pretende publicar levar isso para frente até mostrar no municipio, em alguma (EP) Educação Permanente nossa" (Lírio).

"Posso completar? O que que acontece? Na nossa formação, nós temos muito essa questão da Educação Permanente em Saúde. Então, é um outro instrumento que talvez seria um indicador de qualidade para melhorar alguns processos de trabalho" (Lirio).
\end{abstract}

As evidências apresentadas pelos enfermeiros participantes da pesquisa distinguiu-se em condutas profissionais relacionadas à Educação Permanente em Saúde, instrumentos implementados quanto a melhoria do processo de trabalho adentro da ESF em relação as ações de saúde realizadas nos territórios adstritos para organização da gerência de cuidados.

Os sujeitos envolvidos na pesquisa Socioclínica reelaboram o sentido que atribuem as suas ações e dessa forma os pesquisadores têm acesso a um processo reflexivo que está em produção. A pesquisa transforma os fatos que estuda, ao mesmo tempo em que contribui para a produção dos mesmos ${ }^{10}$.

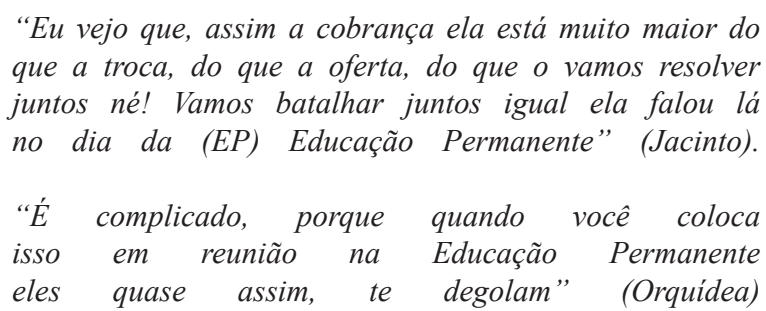

Nesse sentido, o sujeito individual e/ou coletivo 
pode problematizar seu cotidiano de trabalho, com desenvolvimento aos aspectos e instituições os quais ele questiona. Acredita-se, assim, que a Socioclínica Institucional pode atuar na perspectiva de gerar processos de Educação Permanente em Saúde. Ela não consiste em uma modalidade técnica ou protocolo de prática e análise, mas em um meio para se questionarem o objeto e intenções de análise, buscando entender as dinâmicas sociais ${ }^{6}$.

Retratamos os papeis dos enfermeiros na contribuição no atributo das transformações em Educação Permanente em Saúde como ferramenta, contemplando sobre a qualidade da assistência e modificação da realidade e evolução das ações de saúde no campo da Estratégia Saúde da Família.

\section{A Educação Permanente como indicador no entendimento no Processo de Trabalho}

Momento em que a Educação Permanente foi abordada como indicador para entendimento do processo de trabalho uma vez que, os participantes corrobam essa discussão dentro da pesquisa Socioclínica. Cuja finalidade do indicador é contribuir no processo de trabalho.

Os indicadores são medidas-síntese que possuem informação relevante sobre determinadas características e dimensões do estado de saúde e também do desempenho do sistema de saúde. Eles foram desenvolvidos para facilitar a quantificação e a análise das informações produzidas e auxiliar a avaliação da situação sanitária da população, a tomada de decisões baseadas em evidências e a programação de ações de saúde ${ }^{11}$.

Nessa perspectiva o indicador é um movimento continuo na construção coletiva para avaliação das atividades educativas de ensino-aprendizagem dos enfermeiros atuantes na Estratégia Saúde da Família onde ocorreu a pesquisa.

"Enfim... então assim, resumindo o que eu queria falar. Eu acho que na Educação Permanente você poderia indicar como um indicador que poderia ajudar a melhorar até entender o Processo de Trabalho. Acho que é um dispositivo de contribuição" (Lírio)

Para os participantes demandantes de uma pesquisa-ação, o objetivoé, pois, produzir conhecimentos que tenham alguma utilidade para a ação, a partir dos problemas colocados pela prática cotidiana ou, ainda, de um questionamento sobre a origem de certos dispositivos ou modos de pensamento próprios de certos estabelecimentos ou instituições ${ }^{8}$.

Para os pesquisadores, a intenção de conhecimentos situa-se além do espaço do estabelecimento ou do dispositivo em que se realiza o trabalho. Eles perseguem um itinerário de pesquisa de largo fôlego, respondendo a diferentes demandas localizadas ${ }^{10}$.

\begin{abstract}
"Então assim aquelasmesmas questões quetodo mundopassa né, que só muda o local e o nome das pessoas mas que a gente passa e a gente está ali, vez após vez, desde quando eu cheguei que eu ouço algumas EPs (Educação Permanente) em alguns encontros, os mesmos problemas, as mesmas discussões, e a gente não caminha, nada acontece" (Calêndula).
\end{abstract}

Para que todo esse processo aconteça, é necessário que haja análise das implicações do pesquisador e dos demais participantes no desenvolvimento da pesquisa Socioclínica. Analisar as implicações é colocar em análise as relações que os sujeitos estabelecem com as instituições que os perpassam ${ }^{6}$.

[...] a implicação e o engajamento pessoal e coletivo do pesquisador em e por sua práxis cientifica, em função de sua história familiar e libidinal, de suas posições passada e atual nas relações de produção e de classe, e de seu projeto sócio-político em ato, de tal modo que o investimento que resulte inevitavelmente de tudo isso seja parte integrante e dinâmica de toda atividade de conhecimento ${ }^{12}$.

É preciso aprender quando perguntar e quando não perguntar; assim, as entrevistas formais são muitas vezes desnecessárias, e a coleta de informações não se restringe a esse instrumental. Com o tempo, as respostas podem vir ao pesquisador de maneira mais naturalizada para isso, o observador precisa estar sempre à espreita na "esquina", fazendo-se um trocadilho e pronto para captar as informações e perspectivas, até mesmo aquelas que nem eram anteriormente vislumbradas ${ }^{13}$.

A EPS corroba com a Socioclínica Institucional com o intuito de organizar e qualificar o processo de trabalho dos enfermeiros na ESF uma vez que, a gerência de cuidados se faz presente no exercício de atuação do enfermeiro. Sendo assim, a construção coletiva e as discussões que se deram nos encontros nos proporcionou contribuições e desafios quanto ao desenvolvimento das ações em saúde desenvolvidas por enfermeiros na ESF.

\section{Considerações Finais}

A Educação Permanente em Saúde configura-se como uma ferramenta de mobilização para o processo de trabalho da gerência dos cuidados ao se discutir as ações de saúde territórias dos enfermeiros atuantes na Estratégia Saúde da Família ao produzir troca de experiência, aprendizado e reflexão em grupo no qual o processo de trabalho está sempre em movimento.

Dentro da pesquisa Socioclínica Institucional buscamos promover a interação dos participantes no sentido de partilhar questionamentos, problematização do cotidiano, compartilhamentos de ideias, angustias 
e dificuldade. Neste sentido a Educação Permanente em Saúde como ferramenta direcionadora do processo de trabalho proporcionar diferentes olhares entre os enfermeiros ao incrementar suas vivências fortalecendo a construção e produção de pensar e fazer no trabalho.

Os polos abordados nos encontros Socioclínica Institucional, obtivemos a participação dos enfermeiros se deu através da temática Educação Permanente em Saúde uma ferramenta na ESF, com apontamentos para a gerência dos cuidados como processo de trabalho, retratando inovações e análises entre pesquisadores e participantes quanto a multiplicação e organização do processo de trabalho dos enfermeiros em atuação na Estratégia Saúde da Família.

\section{Referências}

1. Brasil. Ministério da Saúde. Secretaria de Gestão do Tra $\neg$ balho e da Educação na Saúde. Política de Educação Per $\neg$ manente e Desenvolvimento para o SUS: caminhos para educação permanente em saúde. Brasília, DF: Ministé $\neg$ rio da Saúde; 2004. 68 p. (Série C. Projetos, Programas e Relatórios). Disponível em: http://bvsms.saude.gov.br/bvs/publicacoes/politica2_vpdf. pdf

2. Campos KA, Santos FM. A educação a distância no âmbito da educação permanente em saúde do Sistema Unico de Saúde (SUS) Rev. Serv. Público Brasília 67 (4) 603-626 out/dez 2016. Disponível em: https://revista. enap.gov.br/index.php/RSP/article/view/1055

3. Bispo Júnior JP, Moreira DC. Educação permanente e apoio matricial: formação, vivências e práticas dos profissionais dos Núcleos de Apoio à Saúde da Família e das equipes apoiadas. Cad. Saúde Pública 2017; 33(9): e00108116. Disponível em: http://www.scielo.br/scielo.php?script=sci arttext\&pid=S0102-311X2017000905010

4. Almeida JRS, Bizerril DO, Saldanha KGH, Almeida MEL. Educação Permanente em Saúde: uma estratégia para refletir sobre o processo de trabalho. Revista da ABENO (2): 7-15, 2016. Disponível em: http:// revodonto.bvsalud.org/scielo.php?script=sci_abstract\&pid=S167959542016 000200003\&lng=es\&nrm=iso\&tlng=pt

5. Costa DW, Parreira BDM, Borges FA et al. Educação em Saúde e empoderamento do usuário da Estratégia Saúde da Família. Rev enferm UFPE on line., Recife, 10(1):96-102 jan., 2016. Disponível em: https://periodicos. ufpe.br/revistas/revistaenfermagem/article/download/10926/12214

6. Rézio LA, Fortuna CM, Borges FA. Pistas para a educação permanente em saúde mental na atenção básica guiada pela Socioclínica Institucional. Rev. Latino-Am. Enfermagem 2019;27: e3204. Disponível em: http://www.scielo.br/scielo.php?pid=S010411692019000100385\&scrip $\mathrm{t}=\mathrm{sci}$ arttext\&tlng=pt

7. Monceau, G. A socioclínica institucional para pesquisa em educação e em saúde. Análise institucional \& saúde coletiva. Hucitec São Paulo. 2013:91103. Disponível em: https://www.researchgate.net/publication/305808891

8. Monceau G. Técnicas Socioclínicas para a análise institucional das práticas sociais. Psicol Rev 2015.

9. Monceau G. Techniques Socio-Cliniques pour l'analyse Institutionnelle des Pratiques. 2012. Disponivel em: https://www. researchgate.net > publication > 288841263_Tecnicas_socioclini.

10. Monceau, G. Transformar as práticas para conhecê-las: pesquisa ação e profissionalização docente. Educação e Pesquisa, v.31, n.3, 2005, p.467482. Disponível em: http://www.scielo.br/pdf/ep/v31n3/a10v31n3.pdf

11. Rede Interagencial de Informação para a Saúde (RIPSA). Indicadores e dados básicos para a saúde no Brasil (IDB): Conceitos e critérios. RIPSA (Rede iREDE Interagencial formações para a saúde) 2019. Disponível em: http://www.ripsa.org.br/vhl/indicadores-e-dados-basicos-para-a-saude-nobrasil-idb/
12. Barbier, René. O conceito de "implicação" na pesquisa-ação em ciências humanas. A pesquisa-ação na instituição educativa. Tradução Estela dos Santos Abreu. Rio de Janeiro: Jorge Zahar, 1985. p. 105-128. Disponível em: http://educonse.com.br/2011/cdroom/eixo\%2014/PDF/Microsoft $\% 20$ Word $\% 20 \% 200 \% 20$ CONCEITO $\% 20$ DE $\% 20$ IMPLICAcaO $\% 20$ EM $\% 20$ PRaTICAS.pdf

13. WHYTE, W. F. Sociedade de esquina: a estrutura social de uma área urbana pobre e degradada. Trad. Maria Lúcia de Oliveira. Rio de Janeiro: Jorge Zahar, 2005. Disponível em: https://periodicos.pucpr.br/index.php/ estudosdecomunicacao/article/view/14594 